\title{
MORTALIDADE POR CÂNCER DE COLO UTERINO E MAMA NO BRASIL: EVIDÊNCIAS REGIONAIS.
}

\author{
Cícera Luana Cruz Tavares ${ }^{1}$; Flaviana Ferreira de Oliveira ${ }^{2}$; Kevellyn Cruz Aguilera ${ }^{2}$; \\ Cláudio Gleidiston Lima da Silva ${ }^{3}$
}

Introdução: $O$ câncer de mama e colo uterino são os que mais acometem mulheres no contexto mundial. O câncer de mama, juntamente com os cânceres de pulmão e colorretal, aparecem entre os mais incidentes em países de alta renda, enquanto o câncer de colo do útero supera os demais tipos em países de baixa renda ${ }^{4}$. A introdução do rastreamento para o câncer de colo do útero em países desenvolvidos provou que essa medida reduziu de forma importante a incidência e a mortalidade da doença e prolongou a sobrevida das pacientes. Isso, no entanto, não foi observado em países de baixa renda onde o acesso a cuidados primários e especializados é limitado ${ }^{5}$. Objetivos: Analisar a evolução da mortalidade por câncer do colo uterino e de mama no Brasil através de indicadores de assistência à saúde e socioeconomicos. Metodologia: Trata-se de uma pesquisa retrospectiva documental, através da base de dados extraídos do Sistema de Informações sobre Mortalidade, os denominadores populacionais do Instituto Brasileiro de Geografia e Estatística, e os indicadores socioeconômicos e assistenciais do Instituto de Pesquisa Econômica e Aplicada, onde foram analisados dados da década de 80 a 2015. Resultados: Evidenciou-se que no Brasil houve queda de mortalidade por câncer de colo uterino em todo o território exceto nas regiões Norte e Nordeste e a partir da década de $90 \mathrm{um}$ declínio no câncer de mama no Brasil nas regiões metropolitanas. Ao passo que houve declínio da taxa de fecundidade pode-se relacionar esse fato aos indicadores socioeconômicos e a taxa de mortalidade por câncer de mama no interior do país, ainda mais prevalente. Os resultados sugerem um mecanismo dinâmico entre exposições de risco determinantes no aparecimento dos cânceres de mama e colo do útero. Conclusão: A queda da mortalidade por câncer do colo uterino foi evidenciada nas regiões Sudeste e Sul e nas regiões metropolitanas do Norte e Nordeste. Os óbitos por câncer de mama começaram a diminuir nas regiões metropolitanas no Sul e Sudeste. A mortalidade declinante do câncer de colo do útero pode refletir a proteção conferida pelo teste de Papanicolaou, porém não se observa esse fato no interior das regiões Norte e Nordeste. A mortalidade é atenuada em função de melhor acesso a medidas diagnósticas e terapêuticas.

Palavras-Chave: Mortalidade; Neoplasia de mama e colo uterino; Medidas diagnósticas e terapêuticas.

\footnotetext{
${ }^{1}$ Acadêmica de Medicina da Faculdade de Medicina Estácio/FMJ. Contato: e-mail: luana.smille@hotmail.com;

${ }^{2}$ Autora, acadêmica de Medicina da Faculdade de Medicina Estácio/FMJ;

${ }^{3}$ Orientador, Doutor, Medico Patologista e docente da Faculdade de Medicina Estácio/FMJ.

${ }^{4}$ BRAY F, JEMAL A, GREY N, FERLAY J, Forman D. Global cancer transitions according to the Human Development Index (2008-2030): a populationbased study. Lancet Oncol, 2012. Lancet Oncol. 2012 Aug;13(8):790-801.

${ }^{5}$ PECORELLI S, FAVALLI G, ZIGLIANI L, ODICINO F. Cancer in women. Int J Gynaecol Obstet; 2003, 82(3):369-79.
}

14 Id on Line Rev. Mult. Psic. V.12, N. 40. 2018 - ISSN 1981-1179 EDIÇÃO ESPECIAL: I CURSO DE ONCOLOGIA DO CARIRI / II JORNADA DE PESQUISA QUANTI-QUALITATIVA EM ONCOLOGIA. JUAZEIRO DO NORTE, 05 A 10 DE MARÇO DE 2018.

Edição eletrônica em http://idonline.emnuvens.com.br/id 